supervision, ensuring that staff and volunteers feel able to take time to focus on themselves and each other.

When developing our campaign, we have engaged in conversation with both staff and volunteers and other service providers and hospices to ensure that the support services we provide best meet the needs of our staff and volunteers. We plan to have different streams of support, some mandatory (clinical supervision) and others that can be utilised as and when required.

\section{P-89 WITNESSING DYING AND DISTRESS: END-OF-LIFE CARE AND THE EMOTIONAL IMPACT ON AMBULANCE CLINICIANS}

Georgina Murphy-Jones, Karina Catley. London Ambulance Service NHS Trust, London, UK

\subsection{6/bmjspcare-2019-HUKNC.112}

Background A two-year programme at a UK ambulance trust has been funded by Macmillan to improve the quality of care provided to end-of-life care patients. Ambulance clinicians manage intense emotions and family reactions during an endof-life care crisis (Waldrop, Clemency, Lindstrom, Cordes, 2015), however, there is limited evidence that examines the emotional impact of such experiences.

Aim Examine the emotional impact of end-of-life care situations on ambulance staff.

Methods An electronic survey collected 258 responses from operational staff to identify support needs and inform service development.

Results Survey results, while not generalisable, highlight an urgent need for further investigation. Three themes were identified:

1. Witnessing the end-of-life and family distress. Situations that mirror personal experience prompted reflection, discomfort and distress. Witnessing families' distress and grief reactions had substantial impact. This was more prevalent when families were unprepared, in denial, or lacking knowledge. Although ambiguous, witnessing a patient or family member of young age had an effect.

2. Lack of services. Inadequate planning and poor provision of other health care services, particularly out-of-hours, resulted in a perceived lack of support for families. Difficulty accessing care for a patient to stay at home had an emotional impact.

3. 'Supporting' family. The role of supporting families was emotionally burdensome. Responses suggested 'support' related to emotional, physical and providing information. Staff managed family expectations through explanation, information sharing and delivering bad news. These conversations had emotional consequences.

Conclusions Supporting unprepared families, difficulty accessing other services and resonating personal experiences all had an emotional impact. Actions to improve staff wellbeing and service development:

- Introduction of Schwartz Rounds to support emotional reflection;

- Pathway development with palliative care services to improve out-of-hours support;

- Education for line managers on providing bereavement support and developing communication skills for clinicians;
- Emotional resilience should be included within the end-oflife care curricula;

- Share results shared with the National Ambulance End-of-life Care Forum.

\section{P-90 WELLBEING@WORK - REDUCING HOSPICE STAFF SICKNESS AND TURNOVER RATES}

Helen Forrow. Marie Curie, Newcastle upon Tyne, UK

10.1136/bmjspcare-2019-HUKNC.113

Following a staff survey, the Senior Management Team (SMT) initially dedicated a whole year to developing a systems wide approach to improving staff wellbeing and engagement across all staff. This initiative was supported by the local commissioners who agreed to support the hospice approach and embed actions into a bespoke CQUIN (Commissioning for Quality and Innovation) scheme (2017/18). In its second year the project was expanded to cover retention and review of working patterns for clinical staff following a significant number of nursing staff leaving within one year of appointment. Work has focussed on increasing staff engagement with local strategy and service developments as well as a strong steer on learning and development. Communication streams and appraisal documentation have been improved as has the management and awareness of sickness and absence.

The aims of the project were to ensure staff received excellent care and support from the hospice in order to improve their working lives. The project aimed to ensure staff were informed and engaged with the hospice strategy and had a personal development plan in place associated with the local ambitions. We aimed to engage staff in strategic developments and increase engagement around local quality and operational changes. We also aimed to reduce staff sickness and therefore provide more efficient, consistent care to our patients. Through a unique approach to wellbeing and mental health the SMT aimed to reduce the impact of work related stress and reduce the emotional burden of care across the hospice team.

Sickness reduced from $7 \%$ to $3.9 \%$ in two years. Robust and effective wellbeing strategy embedded across hospice team. Personal development plans are business specific and individualised to all teams. Uptake is $100 \%$. Staff retention is improved and staff are investing in personal development to improve patient care. Staff engagement is increased and continues to rise.

\section{P-91 CREATING MEANINGFUL VOLUNTEERING IN CLINICAL AREAS FOR YOUNG VOLUNTEERS IN A SCOTTISH HOSPICE}

Maggie Young, Karen Filsell. St Columba's Hospice, Edinburgh, UK

\subsection{6/bmjspcare-2019-HUKNC.114}

Background 2018 was Year of the Young Person in Scotland. The hospice traditionally offered existing single-department roles to young people wanting clinical experience for college or work. As part of its Leadership Programme, Volunteer Services wanted an innovative and sustainable project offering 